\title{
Using epidemiological evidence to forecast population need for early treatment programmes in mental health: a generalisable Bayesian prediction methodology applied to and validated for first-episode psychosis in England
}

Keltie McDonald*, Tao Ding*, Hannah Ker, Thandiwe Rebecca Dliwayo, David P.J. Osborn, Pia Wohland, Jeremy W. Coid, Paul French, Peter B. Jones, Gianluca Baio and James B. Kirkbride

\section{Background}

Mental health policy makers require evidence-based information to optimise effective care provision based on local need, but tools are unavailable.

\section{Aims \\ To develop and validate a population-level prediction model for need for early intervention in psychosis (EIP) care for first-episode psychosis (FEP) in England up to 2025, based on epidemiological evidence and demographic projections.}

\section{Method}

We used Bayesian Poisson regression to model small-area-level variation in FEP incidence for people aged 16-64 years. We compared six candidate models, validated against observed National Health Service FEP data in 2017. Our best-fitting model predicted annual incidence case-loads for EIP services in England up to 2025, for probable FEP, treatment in EIP services, initial assessment by EIP services and referral to EIP services for 'suspected psychosis'. Forecasts were stratified by gender, age and ethnicity, at national and Clinical Commissioning Group levels.

\section{Results}

A model with age, gender, ethnicity, small-area-level deprivation, social fragmentation and regional cannabis use provided best fit

\section{to observed new FEP cases at national and Clinical} Commissioning Group levels in 2017 (predicted 8112, 95\% Cl 7623-8597; observed 8038, difference of 74 [0.92\%]). By 2025, the model forecasted 11067 new treated cases per annum $(95 \% \mathrm{Cl}$ 10383-11 740). For every 10 new treated cases, 21 and 23 people would be assessed by and referred to EIP services for suspected psychosis, respectively.

\section{Conclusions}

Our evidence-based methodology provides an accurate, validated tool to inform clinical provision of EIP services about future population need for care, based on local variation of major social determinants of psychosis.

\section{Keywords}

Psychotic disorders; epidemiology; Bayesian statistics; prediction; health services research.

\section{Copyright and usage}

(C) The Author(s), 2021. Published by Cambridge University Press on behalf of the Royal College of Psychiatrists. This is an Open Access article, distributed under the terms of the Creative Commons Attribution licence (http://creativecommons.org/ licenses/by/4.0/), which permits unrestricted re-use, distribution, and reproduction in any medium, provided the original work is properly cited.

\section{Background}

The past decade has witnessed an unprecedented transformation in public perception of mental health, ${ }^{1}$ with political commitment ${ }^{2,3}$ to address substantial disparities between physical and mental healthcare. ${ }^{4}$ This has begun to have an impact on mental healthcare provision, which is undergoing substantial reconfiguration in many regions, including the USA, ${ }^{5}$ Canada, ${ }^{6}$ Australia $^{7}$ and northern Europe. $^{2,8,9}$ One such example is early intervention in psychosis (EIP) services, which seek to provide multidisciplinary care for people with an emerging psychosis, informed by an evidence base that suggests that a longer duration of untreated psychosis is associated with less favourable health and social outcomes. ${ }^{10}$ These services have rapidly gained traction in several countries, including England, based on clinical evidence for their efficacy, ${ }^{11}$ effectiveness ${ }^{11,12}$ and potential cost-effectiveness ${ }^{13}$ over the short to medium term. Effects on longer-term outcomes, particularly in the absence of sustained intervention, are less apparent, ${ }^{14}$ and are a challenge to providing sustainable care models for people experiencing psychosis.

* Joint first authors

\section{Evidence-based public mental health}

Optimising this care requires a broader evidence-based, pragmatic approach, ${ }^{15}$ incorporating epidemiological knowledge to aid decision-making, to effectively allocate resources to EIP services based on anticipated local need in different populations. For example, age, gender and urbanicity have been consistently associated with the incidence of psychotic disorders in the UK, Europe and potentially beyond, ${ }^{16}$ and their local distributions could therefore inform population-level need for treatment each year. Such populationbased approaches are increasingly recognised as vital to effective public mental health, but few examples are available to inform local and national mental health policy. ${ }^{15,17}$

One example previously applied to population-level need for EIP care in England is known as the PsyMaptic model (Psychiatric Mapping Translated into Innovations for Care). ${ }^{18,19}$ Based on empirical epidemiological estimates of the incidence of first-episode psychosis (FEP) by age, gender, ethnicity and selected area-level characteristics such as deprivation, this model predicted the incidence (number and rate of new cases) in different population groups and regions based on the population structure of the 2011 Census of Great Britain. This model has subsequently informed national policy-making in the $\mathrm{UK}^{20,21}$ including 
implementation guidelines for the landmark 'Access and Waiting Time' standard for EIP care in $2016,{ }^{20}$ as part of the National Health Service and Department of Health's 'Five-Year Forward View for Mental Health', ${ }^{2}$ which legislated commitment to parity of esteem between physical and mental health. ${ }^{22}$ This standard mandated that at least $60 \%$ of all people aged $14-65$ years who are referred to EIP services for 'suspected psychosis' must have been assessed, and where suitable, commenced a National Institute of Health and Care Excellence (NICE)-concordant, ${ }^{22,23}$ evidence-based ${ }^{24,25}$ package of EIP care within 14 days. However, although there is emerging evidence that most EIP services in England are already exceeding the waiting time target, ${ }^{26}$ achieving fidelity to other targets in the standard, including offering cognitive-behavioural therapy for psychosis, family interventions and supported employment and education programmes, has proved challenging, ${ }^{26}$ and may erode potential beneficial outcomes expected for patients available when full-fidelity EIP care is offered. ${ }^{17}$ A prerequisite to achieving such fidelity is that mental health service policy makers, commissioners and providers have access to timely and accurate information about future local need for EIP care, so that services can be appropriately resourced to deliver effective, optimised evidence-based care.

Nonetheless, the previously published PsyMaptic tool ${ }^{18}$ had limited generalisability to forecast future need for EIP care. For example, it was restricted to (a) a static denominator population, using the 2011 Census; (b) incidence data ascertained before the national introduction of EIP services in 2002; (c) social determinants of health data at a local authority level (serving large, heterogenous areas; median population in 2018: 126678 people $^{27}$ ) and (d) ICD-10 diagnostic criteria for psychotic disorders, and not the broader need for assessment and treatment generated by referrals to EIP services for suspected psychosis. ${ }^{20}$

\section{Aim}

To overcome these limitations and facilitate generalisability of our methodology to other settings, we developed a new, populationbased prediction model applied to psychosis care in England, validated against observed national routine data. Our methodology forecasted small-area need for EIP provision up to 2025 to inform the 'NHS Long-Term Plan'28 and 'Mental Health Implementation Plan in England', ${ }^{29}$ which have recently reaffirmed and strengthened their commitment to EIP care, taking into account projected changes in the population at risk in England over the next 5 years.

\section{Method}

We followed the transparent reporting of multivariable prediction modell for individual prognosis or diagnosis reporting guidelines for prediction modelling (Supplementary Box 1 available at https://doi.org/10.1192/bjp.2021.18).

\section{Model development}

Seed data

Empirical incidence data were pooled from the three largest epidemiological catchment area studies of psychotic disorders in England in the past 25 years, which used similar methodologies, as described in detail elsewhere ${ }^{30-33}$ (Supplementary Section 1): the Aetiology and Ethnicity in Schizophrenia and Other Psychoses (ÆSOP), ${ }^{30}$ the East London First Episode Psychoses $(\text { ELFEP })^{32,33}$ and Social Epidemiology of Psychoses in East Anglia $(\text { SEPEA })^{31}$ studies.
Outcome

These studies included incidence data on all people aged between 16-64 years who presented to services (including EIP ${ }^{31}$ ) in each catchment area for suspected psychosis, and who later met research-based criteria for a diagnosis of for non-affective psychotic disorder (ICD-10 codes F20-29), affective psychotic disorder (ICD-10 codes F30-33) or substance-induced psychotic disorder (ICD-10 code F1X.5). Individuals with an organic basis to their disorder or profound intellectual disability were excluded.

\section{Predictors}

Participants were linked to their small-area neighbourhood of residence at first presentation (ÆSOP/ELFEP: 2001 Census Area Statistics wards; SEPEA: 2011 Census merged wards). For each ward, we obtained measures of relevant socioenvironmental data, guided by previous models and the wider literature, ${ }^{18,34,35}$ including population density; social fragmentation; own-group ethnic density; multiple deprivation; inequality and the gender-specific, age-standardised prevalence of self-reported past-year cannabis use in the population (Supplementary Section 2). We stratified our seed data-set by age group $(16-17,18-19,20-24,25-29,30-34,35-39$, $40-44,45-49,50-54,55-59$ and $60-64$ years), gender and selfassigned ethnicity (based on a priori evidence about risk: $:^{34,36}$ White British, Irish, Gypsy and Traveller; White other; Black Caribbean and Black other; Black African; Indian; Pakistani; Bangladeshi; mixed; and all other ethnicities) at ward level. We recorded the count of FEP cases and person-years at risk in each strata, estimated from the nearest decennial census to the case ascertainment period (Supplementary Section 3). Ward- and regionallevel covariates were appended to this data-set.

\section{Model building}

We modelled the count of new (incidence) cases of psychotic disorders by using Poisson regression in a Bayesian framework. A Poisson distribution was preferred to a negative binomial distribution as there was no evidence of overdispersion within the seed dataset (Supplementary Table 1). The Bayesian approach allowed us to combine this data-set with a priori knowledge about the epidemiology of psychotic disorders, specified as prior probability distributions on the covariates to be estimated, informed by published evidence $^{34-37}$ (Supplementary Section 4, Figs 1-3 and Tables 2-5). We fitted our models by using integrated nested Laplace approximation $^{38}$ to estimate the posterior distribution for the relevant parameters. Then, to fully characterise the uncertainty in the estimates and the predictions, we used Monte Carlo simulation to randomly sample 1000 values from the joint posterior distributions of each model parameter, simultaneously accounting for any correlation present between parameters in the model. This allowed us to capture the full uncertainty around the effect of each potential covariate on FEP incidence rates, which we expressed as posterior relative risks with their $95 \%$ credible interval estimates.

Initial modelling suggested that ethnic density (relative risk $1.001,95 \%$ CI $0.998-1.005$ ) and inequality (relative risk $0.90,95 \%$ CI 0.50-1.62) were not associated with FEP incidence in our seed data-set, and were removed from further consideration. From the remaining covariates, we considered six a priori candidate models. We included age group, gender, their interaction and ethnic group in all models, with different permutations of deprivation, population density, social fragmentation and cannabis use fitted in each model. Person-years at risk were treated as an offset in the models. 


\section{Out-of-sample prediction}

\section{Denominator and socioenvironmental data}

We estimated the projected population at risk, aged 16-64 years, for all Census merged wards in England $(N=7678)$ between 20172025, stratified by age group, gender and ethnicity (as before). Projected population estimates up to 2025 were obtained from demographic forecasts with an established methodology, ${ }^{39,40}$ using 2011 Census data as a baseline, accounting for year-on-year changes in birth and death rates, immigration and emigration flows, and including assumptions about the impact of Brexit beyond $2020^{40}$ (Supplementary Section 5). Population projections for the City of London (four wards) and Isles of Scilly (one ward) were excluded because of substantial overestimation of the ward population, when compared with Office for National Statistics 2017 mid-year population estimates. ${ }^{41}$ For socioenvironmental covariates, we used the latest available routine data at the time of model development for deprivation (2015), ${ }^{42}$ social fragmentation (2011), population density (re-estimated for each year between 2017-2025, based on ward-level projected populations) and regional cannabis prevalence $(2014)^{43}$ (Supplementary Section 2).

\section{FEP prediction}

Posterior relative risk coefficients from each model were applied to the projected denominator data in a given year (2017-2025) at ward level, to estimate the predicted number of incident FEP cases in each age-gender-ethnic stratum in each ward. Within our Bayesian framework, we performed 1000 model simulations, sampling from the posterior distribution to yield the mean predicted FEP cases per stratum, and corresponding 95\% confidence interval, derived from the $2.5 \%$ and $97.5 \%$ quantiles. This allowed us to aggregate prediction data to Clinical Commissioning Group (CCG) level and the national level by gender, broad age group (16-64, 16-35 and 36-64 years; consistent with those most relevant to EIP care in England) and ethnicity for any given year (20172025) (Supplementary Section 6). CCGs are autonomous, clinically led, statutory National Health Services (NHS) bodies responsible for the planning and commissioning of health services in local areas. ${ }^{44}$

\section{Model validation}

Apparent validation

Apparent validity of the six candidate models was evaluated with the deviance information criterion (DIC), with a smaller value indicating better fit. ${ }^{34,45}$

\section{External validation}

To externally validate our models, we compared predicted FEP data based on the 2017 denominator population, with observed national data available from NHS Digital's Mental Health Services Dataset (MHSDS) in the closest (financial) year available (April 2017 to March 2018; henceforth '2017'). Comparisons were matched for the EIP age range served by each CCG in 2017 (Supplementary Section 7). ${ }^{46}$ The MHSDS records data from all health records for people in contact with mental health services in England. From this data-set, we extracted data for each CCG in England $(N=$ 207 ) on the total number of new people (a) referred to mental health services for suspected psychosis; (b) accepted for assessment by EIP services; (c) who commenced EIP treatment for FEP and (d) who were probable FEP cases, based on empirical evidence that approximately $14 \%$ of those who commenced treatment for FEP in EIP services do not go onto to fulfil operationalised criteria for ICD-10 psychotic disorder. ${ }^{31}$ Those not meeting criteria for probable FEP in categories a-c implicitly included people meeting the clinical high risk for psychosis (CHR-P) criteria, who are not currently separately disaggregated within the MHSDS data-set. Formal definitions of each of these nested levels, henceforth referred to as referred/assessed/treated/probable FEP case-loads, are given in Supplementary Section 7.

We inspected external validity at the CCG level by estimating correlation coefficients $(r)$ between observed and predicted probable FEP counts, the $r^{2}$ statistic and root-mean-square error (RMSE), with higher $r^{2}$ and lower RMSE indicating better model fit. We inspected calibration plots of predicted versus observed FEP counts and compared the difference in predicted and observed FEP counts, expressed as a rate per 100000 person-years at the CCG level. At the national level, we compared the difference between predicted and observed case-loads, expressed as a percentage, for the total count and by broad age group, gender and ethnic group. Choice of our best-fitting model was determined by consensus agreement between our authorship group, after evaluation of all apparent and external validation metrics.

\section{Missing data}

We excluded two CCGs from external validation (NHS Birmingham \& CrossCity CCG and NHS Sandwell and West Birmingham CCG) because of problems with data validity in the MHSDS during this reporting period (C. Money, personal communication, 2019). These CCGs were reinstated for prediction forecasting (see below) between 2019 and 2025. MHSDS data were complete with respect to national- and CCG-level totals and by broad age group (16-35 and 36-64 years). Ten (0.1\%) observed probable FEP cases were missing information on gender, and were excluded from gender-specific validation. Ethnicity data were missing for 820 (10.2\%) observed probable FEP cases, which would have affected model validity by ethnicity without imputation, which we handled via imputation in sensitivity analyses (Supplementary Section 8).

\section{Forecasting}

Our best-fitting model was used to forecast predicted probable FEP case-loads in England between 2019-2025, using the relevant denominator projections for each year. Predictions and their 95\% confidence intervals, stratified by broad age group, gender and ethnicity, were aggregated to 2019 CCG and national levels for dissemination. We also forecasted new referred, assessed and treated caseloads (implicitly including CHR-P individuals) per annum by multiplying predicted probable FEP case-loads by the ratios derived from the observed data in the 2017 MHSDS (Supplementary Section 9). All prediction forecasts were expressed as incidence counts, and rates per 100000 persons-years.

\section{Software}

Data-set generation and validation were performed in Stata version 15 for Windows, ${ }^{47}$ prediction modelling was conducted with the integrated nested Laplace approximation package in $\mathrm{R}$ version 3.5 for Windows (R Foundation, Austria; see https://www.r-project. org/), ${ }^{38}$ and out-of-sample prediction using matrix multiplication was performed in $\mathrm{R}^{48}$

\section{Ethics}

The authors assert that all procedures contributing to this work comply with the ethical standards of the relevant national and institutional committees on human experimentation, and with the Helsinki Declaration of 1975, as revised in 2008. All procedures involving human patients were approved by NHS Health Research Authority (approval reference 19/HRA/0145). Consent was not required for this study, which was based on secondary 
Table 1 Summary of FEP data from the $Æ$ ESOP, ELFEP and SEPEA studies

\begin{tabular}{|c|c|c|c|c|c|}
\hline & \multicolumn{4}{|c|}{ Cases, $n(\%)$} & \multirow[b]{2}{*}{ Total person-years } \\
\hline & AESOP & ELFEP $^{a}$ & SEPEA ${ }^{a}$ & Total cases & \\
\hline Person-years at risk & 1653020 & 840587 & 2021772 & - & 4515379 \\
\hline Total & 551 (33.6) & $428(26.1)$ & $659(40.2)$ & $1638(100.0)$ & - \\
\hline \multicolumn{6}{|l|}{ Age group, years } \\
\hline $16-17$ & $22(4.0)$ & - & 77 (11.7) & $99(6.0)$ & $226029(5.0)$ \\
\hline $18-19$ & $51(9.3)$ & $37(8.6)$ & $110(16.7)$ & $198(12.1)$ & 303055 (6.7) \\
\hline $20-24$ & $119(21.6)$ & $91(21.3)$ & 232 (35.2) & $442(27)$ & $851113(18.8)$ \\
\hline $25-29$ & $107(19.4)$ & $116(27.1)$ & $142(21.6)$ & 365 (22.3) & 890523 (19.7) \\
\hline $30-34$ & 90 (16.3) & $63(14.7)$ & 86 (13.1) & $239(14.6)$ & 860693 (19.1) \\
\hline $35-39$ & 60 (10.9) & $43(10.1)$ & $12(1.8)$ & $115(7.0)$ & 418069 (9.3) \\
\hline $40-44$ & $37(6.7)$ & $28(6.5)$ & - & $65(4.0)$ & $257386(5.7)$ \\
\hline $45-49$ & $21(3.8)$ & $23(5.4)$ & - & $44(2.7)$ & $208330(4.6)$ \\
\hline $50-54$ & $18(3.3)$ & $11(2.6)$ & - & $29(1.8)$ & $198414(4.4)$ \\
\hline $55-59$ & $14(2.5)$ & $10(2.3)$ & - & $24(1.5)$ & $157696(3.5)$ \\
\hline 60-64 & $12(2.2)$ & $6(1.4)$ & - & $18(1.1)$ & 144071 (3.2) \\
\hline \multicolumn{6}{|l|}{ Gender } \\
\hline Female & 231 (41.9) & 169 (39.5) & $222(33.7)$ & $622(38.0)$ & 2240659 (49.6) \\
\hline Male & $320(58.1)$ & $259(60.5)$ & 437 (66.3) & $1016(62.0)$ & $2274720(50.4)$ \\
\hline \multicolumn{6}{|l|}{ Ethnicity } \\
\hline White British, Irish and Traveller & $262(47.6)$ & $98(22.9)$ & $498(75.6)$ & $858(52.4)$ & $3288403(72.8)$ \\
\hline White other & $32(5.8)$ & $56(13.1)$ & $60(9.1)$ & $148(9.0)$ & $354296(7.8)$ \\
\hline Black Caribbean & $126(22.9)$ & $70(16.4)$ & $10(1.5)$ & $206(12.6)$ & $168884(3.7)$ \\
\hline Black African & 69 (12.5) & $67(15.7)$ & $22(3.3)$ & $158(9.7)$ & $172731(3.8)$ \\
\hline Indian & $10(1.8)$ & $25(5.8)$ & $2(0.3)$ & $37(2.3)$ & $108359(2.4)$ \\
\hline Pakistani & $8(1.5)$ & $16(3.7)$ & $17(2.6)$ & $41(2.5)$ & $69373(1.5)$ \\
\hline Bangladeshi & $1(0.2)$ & $64(15.0)$ & $6(0.9)$ & $71(4.3)$ & $114754(2.5)$ \\
\hline Mixed & $21(3.8)$ & $18(4.2)$ & $18(2.7)$ & $57(3.5)$ & 97289 (2.2) \\
\hline Other & $22(4.0)$ & $14(3.3)$ & $26(4.0)$ & $62(3.8)$ & $141290(3.1)$ \\
\hline
\end{tabular}

use of aggregated, anonymised data from the ÆSOP, ELFEP and SEPEA studies and similarly aggregated NHS MHSDS data.

\section{Results}

\section{Seed data sample characteristics}

From our seed data-set, we included 1638 cases of FEP from 4515 379 person-years at risk (Table 1). As typical of FEP incidence samples, ${ }^{34}$ most cases were male (62\%), younger than 30 years old at first contact (ÆSOP 54\%, ELFEP 57\%) and with an overrepresentation of participants from Black and minority ethnic backgrounds relative to the local at-risk population (varying from $24 \%$ in SEPEA $^{49}$ to $77 \%$ in $\operatorname{ELFEP}^{33}$ ).

\section{Apparent validation}

Apparent validation of our models suggested that inclusion of arealevel predictors (Table 2, models 2-6, DIC 11 531.88-11 539.75) improved model fit over a model fitted solely with individual-level covariates (model 1: DIC 11614.04); DIC values were equivocal for models 2 and 4-6 (Table 2). Full model parameter specifications (Supplementary Table 6) showed elevated posterior relative risk for young men and several ethnic minority groups, particularly people of Black Caribbean (relative risk model $4_{4} 4.80,95 \%$ CI 4.08-5.63) and Black African (relative risk model 43.33 , 95\% CI 2.78-3.97) ethnicity, consistent with the available literature. ${ }^{34}$ Population density was weakly associated with FEP incidence (relative risk model $_{5} 1.06$, 95\% CI 0.99-1.12). Deprivation showed a non-linear relationship with FEP incidence, with exponentially higher rates at increasingly levels of deprivation (Supplementary Fig. 3). In contrast to expectations, a 1-s.d. increase in social fragmentation was associated with lower incidence (relative risk model $4_{4} 0.92,95 \%$ CI $0.87-0.97$ ). As expected, and driven by prior information, ${ }^{35}$ lifetime self-reported cannabis use was strongly associated with psychosis incidence (relative risk model $4_{4} 1.41,95 \%$ CI 1.16-1.72).

\section{External validation}

National level

In 2017, 22803 new referrals for suspected psychosis were recorded in the MHSDS across the 205 CCG included for validation; 89.9\% $(n=20492)$ were subsequently accepted for EIP assessment, $35.2 \%(n=9346)$ commenced EIP treatment and 35.2\% $(n=8038$; $86 \%$ of the treated case-load) met our definition of probable FEP. For the same period, model 4 (individual covariates, deprivation, social fragmentation and cannabis prevalence) predicted 8112 FEP cases per annum (95\% CI 7623-8597), giving the lowest error of any model at the national level $(n=+74,+0.92 \%)$, compared with the observed probable FEP case-load (Table 2).

All models performed similarly against national observed probable FEP case-loads stratified by major age group, gender and ethnic group (Supplementary Tables 7-9). Model 4 (Table 3), for example, showed good accuracy by gender (Table 3) and ethnicity after imputation for missing observed data (Supplementary Section 8 and Table 9). Nonetheless, all models tended to underpredict FEP case-loads aged 16-35 years (e.g. model 4: $n=-541,-9.2 \%$ ), and, correspondingly, overpredicted case-loads aged 36-64 years (e.g. model 4: $n=+615,+29.0 \%)$ compared with observed probable FEP case-loads in the MHSDS data-set.

\section{CCG level}

At the CCG level, fit indices (Table 2) suggested that models 2-6 (with area-level covariates) provided a better fit to the data than model 1 (individual-level covariates only). Differences in fit indices between models for models 2-6 were small, although model 4 was associated 


\begin{tabular}{|c|c|c|c|c|c|c|}
\hline Covariates & $\begin{array}{l}\text { Model } 1 \\
\begin{array}{l}\text { Age, gender, agexgender, } \\
\text { ethnicity }\end{array}\end{array}$ & $\begin{array}{l}\text { Model } 2 \\
\text { Model } 1 \text { plus deprivation, social } \\
\text { fragmentation, }\end{array}$ & $\begin{array}{l}\text { Model } 3 \\
\text { Model } 1 \text { plus deprivation, } \\
\text { population density }\end{array}$ & $\begin{array}{l}\text { Model } 4 \\
\text { Model } 2 \text { plus cannabis } \\
\text { use }\end{array}$ & $\begin{array}{l}\text { Model } 5 \\
\text { Model } 4 \text { plus population } \\
\text { density }\end{array}$ & $\begin{array}{l}\text { Model } 6 \\
\text { Model } 2 \text { plus population } \\
\text { density }\end{array}$ \\
\hline $\begin{array}{l}\text { Apparent validity } \\
\text { Model DIC }\end{array}$ & 11614.04 & 11533.86 & 1153975 & 11533.72 & 11531.93 & 1153188 \\
\hline & \multicolumn{6}{|c|}{$\begin{array}{l}\text { External validity } \\
\text { National level }\end{array}$} \\
\hline Observed cases, ${ }^{a} n$ & 8038 & 8038 & 8038 & 8038 & 8038 & 8038 \\
\hline Predicted cases, $n(95 \% \mathrm{Cl})^{\mathrm{b}}$ & 8984 (8497 to 9460$)$ & 8137 (7642 to 8637$)$ & 8362 (7907 to 8851$)$ & 8112 (7623 to 8597) & 8187 (7722 to 8707) & 8205 (7716 to 8763) \\
\hline Difference, $n(\%)$ & $946(11.77)$ & $99(1.24)$ & $324(4.04)$ & $74(0.92)$ & $149(1.85)$ & $167(2.08)$ \\
\hline Correlation coefficient, $R$ & 0.70 & 0.74 & 0.74 & 0.74 & 0.73 & 0.73 \\
\hline Calibration slope, $\beta$ (s.e.) & $0.66(0.05)$ & $0.64(0.04)$ & $0.69(0.04)$ & $0.64(0.04)$ & $0.64(0.04)$ & $0.64(0.04)$ \\
\hline $\begin{array}{l}\text { Calibration intercept } \\
\text { Rate difference per } 100000 \text { person- } \\
\text { years between predicted and } \\
\text { observed, } n(\%)^{d}\end{array}$ & 18.08 & 14.90 & 14.21 & 14.84 & 15.00 & 15.03 \\
\hline$<-20$ & $13(6.34)$ & $15(7.32)$ & $14(6.83)$ & $15(7.32)$ & $15(7.32)$ & $15(7.32)$ \\
\hline-20 to -11 & $24(11.71)$ & $21(10.24)$ & $22(10.73)$ & $22(10.73)$ & $23(11.22)$ & $23(11.22)$ \\
\hline-10 to 10 & $109(53.17)$ & $123(60.00)$ & $122(59.51)$ & $123(60.00)$ & $121(59.02)$ & $121(59.02)$ \\
\hline
\end{tabular}




\begin{tabular}{|c|c|c|c|c|c|c|c|c|c|}
\hline & \multirow{3}{*}{$\begin{array}{l}2017 \text { Population at } \\
\text { risk }^{\mathrm{b}}\end{array}$} & \multicolumn{3}{|c|}{$\begin{array}{l}\text { Observed probable } \\
\text { FEP (MHSDS) }\end{array}$} & \multicolumn{3}{|c|}{ Predicted FEP (PsyMaptic-A model 4) } & \multicolumn{2}{|c|}{$\begin{array}{c}\text { Difference } \\
\text { (predicted } \\
\text { minus } \\
\text { observed) }\end{array}$} \\
\hline & & \multicolumn{2}{|c|}{ Cases } & \multirow[t]{2}{*}{ Rate } & \multicolumn{2}{|l|}{ Cases } & \multirow[t]{2}{*}{ Rate $(95 \% \mathrm{Cl})$} & \multirow{2}{*}{\multicolumn{2}{|c|}{$\%$}} \\
\hline & & $n$ & $\%$ & & $n(95 \% \mathrm{Cl})$ & $\%$ & & & \\
\hline Total, age-matched & 32125420 & 8038 & 100.00 & 25.02 & $8112(7623-8597)$ & 100.00 & $25.25(23.73-26.76)$ & 74 & 0.92 \\
\hline \multicolumn{10}{|l|}{ Age, years } \\
\hline 16-35 & 14333850 & 5919 & 73.64 & 41.29 & $5378(5078-5695)$ & 66.30 & $37.52(35.42-39.73)$ & -541 & -9.15 \\
\hline $36-64$ & 17791569 & 2119 & 26.36 & 11.91 & 2734 (2424-3053) & 33.70 & $15.37(13.63-17.16)$ & 615 & 29.02 \\
\hline \multicolumn{10}{|l|}{ Gender } \\
\hline Female & 16046762 & 3240 & 40.31 & 20.19 & 3178 (2899-3467) & 39.18 & $19.8(18.06-21.61)$ & -62 & -1.92 \\
\hline Male & 16078658 & 4790 & 59.59 & 29.79 & 4934 (4597-5284) & 60.82 & 30.69 (28.59-32.86) & 144 & 3.00 \\
\hline Unknown ${ }^{c}$ & & 10 & 0.12 & & & & & & \\
\hline \multicolumn{10}{|l|}{ Ethnicity } \\
\hline $\begin{array}{l}\text { White British, White Irish and } \\
\text { Traveller }\end{array}$ & 23997617 & 4684 & 58.27 & 19.52 & 4570 (4235-4907) & 56.33 & 19.04 (17.65-20.45) & -114 & -2.44 \\
\hline White other & 2474534 & 531 & 6.61 & 21.46 & 767 (652-897) & 9.45 & $30.99(26.36-36.26)$ & 236 & 44.43 \\
\hline Black Caribbean & 538118 & 370 & 4.60 & 68.76 & $538(471-619)$ & 6.63 & 99.95 (87.53-115.11) & 168 & 45.36 \\
\hline Black African & 787915 & 323 & 4.02 & 40.99 & $593(496-688)$ & 7.31 & $75.22(62.93-87.31)$ & 270 & 83.49 \\
\hline Indian & 1060364 & 144 & 1.79 & 13.58 & $281(202-386)$ & 3.47 & $26.54(19.09-36.37)$ & 137 & 95.43 \\
\hline Pakistani & 705815 & 237 & 2.95 & 33.58 & $370(272-505)$ & 4.56 & 52.39 (38.52-71.49) & 133 & 56.03 \\
\hline Bangladeshi & 278900 & 109 & 1.36 & 39.08 & 125 (96-156) & 1.54 & $44.77(34.52-55.82)$ & 16 & 14.56 \\
\hline Mixed & 728404 & 249 & 3.10 & 34.18 & $489(368-615)$ & 6.03 & 73.33 (56.43-94.26) & 240 & 96.36 \\
\hline Other & 1553752 & 570 & 7.09 & 36.69 & $380(295-476)$ & 4.68 & $27.38(21.57-34.91)$ & -190 & -33.42 \\
\hline Unknown ${ }^{c}$ & & 820 & 10.20 & & & & & -820 & -10.20 \\
\hline \multicolumn{10}{|c|}{$\begin{array}{l}\text { Rate shows the incidence rate per } 100000 \text { person-years. FEP, first-episode psychosis; MHSD, Mental Health Services Dataset; CCG, Clinical Commissioning Group. } \\
\text { a. Predicted data were age-matched to observed MHSDS data, according to the corresponding age range served by each CCG as reported in the Early Intervention in Psychosis Network } \\
\text { national audit for the same period (see Supplementary Section } 7 \text { for further details). Not all CCGs served the entire population aged } 16-64 \text { years, so the figures in this table should not be } \\
\text { interpreted as total predicted cases in England for a given stratum. For total predicted case-load sizes in England, for 2019-2025, see Supplementary Table } 10 . \\
\text { b. Reflects the total population according to age ranges accepted by individual CCGs. } \\
\text { c. Includes unknown, indeterminate and invalid values. }\end{array}$} \\
\hline
\end{tabular}

with lowest RMSE and joint-highest $r^{2}$ correlation coefficients (with models 2 and 3). For all models, calibration slopes were positive (e. g. model 4: $\beta=0.64$; s.e. 0.04; Table 2, Supplementary Fig. 4), indicating good agreement between observed and predicted probable FEP case-loads. For model 4, 60\% (123 of 205) of predicted probable FEP case-loads at the CCG level were within \pm 10 cases per 100000 person-years of the observed case-loads, with $87 \%$ (179 of 205) within \pm 20 cases per 100000 person-years (Table 2).

\section{Candidate model selection}

Models 2-6 generally yielded similar apparent and external validation indices, but we interpreted model 4 as performing most consistently across all parameters (Tables 2 and 3). Visual inspection of maps of observed and predicted FEP case-loads for CCGs in 2017 indicated good apparent validity (Supplementary Fig. 5), although some spatial variation in differences remained evident, particularly in South England (Supplementary Fig. 6c).

\section{Forecasting}

Using model 4, we forecasted referred, assessed, treated and probable FEP case-loads in England between 2019 and 2025, based on population projections for each year (Supplementary Fig. 7 and Table 10). For 2020, our model predicted a new referred case-load of 24499 (95\% CI $22930-25$ 991), an assessed case-load of 22033 (95\% CI 20622-23 375), a treated case-load of 10516 (95\% CI 9843-11 157) and a probable FEP case-load of 9066 (95\% CI 8485-9618) aged 16-64 years (predicted probable FEP incidence rate of 25.2 cases per 100000 person-years, 95\% CI 23.6-26.8). Between 2019 and 2025, predicted treated case-loads increased by $6.2 \%$, on average, but we could not exclude the possibility of no change or a small decline in case-loads over time (95\% CI $-3.2 \%$ to $15.6 \%$; Supplementary Table 10 ).
Forecasted FEP incidence varied geographically (for example, in 2020, see Fig. 1), with higher rates in CCGs serving most major conurbations, including Greater London, Greater Manchester, Bradford and Birmingham and the Midlands (Supplementary Table 11). We also predicted that some CCGs with relatively low predicted incidence rates would have large predicted counts of cases (i.e. new case-load sizes), given the large at-risk populations and geographical areas they served (Supplementary Table 12). Complete forecast prediction data at CCG and national levels for 2019-2025 is available at www.psymaptic.org via an open-access web visualisation platform and downloadable data-sets.

\section{Discussion}

\section{Principal findings}

We developed and validated a population-level prediction model to forecast need for mental healthcare, here applied to referral to, assessment by and treatment for suspected psychosis in EIP services in England, using robust epidemiological data and small-area population projections. Our best-fitting model yielded acceptable validity against observed routine data on probable FEP at the CCG level in England for 2017, from which we extrapolated predictions up to 2025 based on small-area population forecasts. Our model also forecasted additional levels of need generated by referred, assessed and treated case-loads to provide a comprehensive, evidence-based tool for EIP planning, consistent with the timeframe of the 'NHS LongTerm Plan'28 and 'Mental Health Implementation Plan'. 29

\section{Strengths and weaknesses}

Our model has a number of strengths. We synthesised robust epidemiological data on psychosis risk, prior knowledge and 


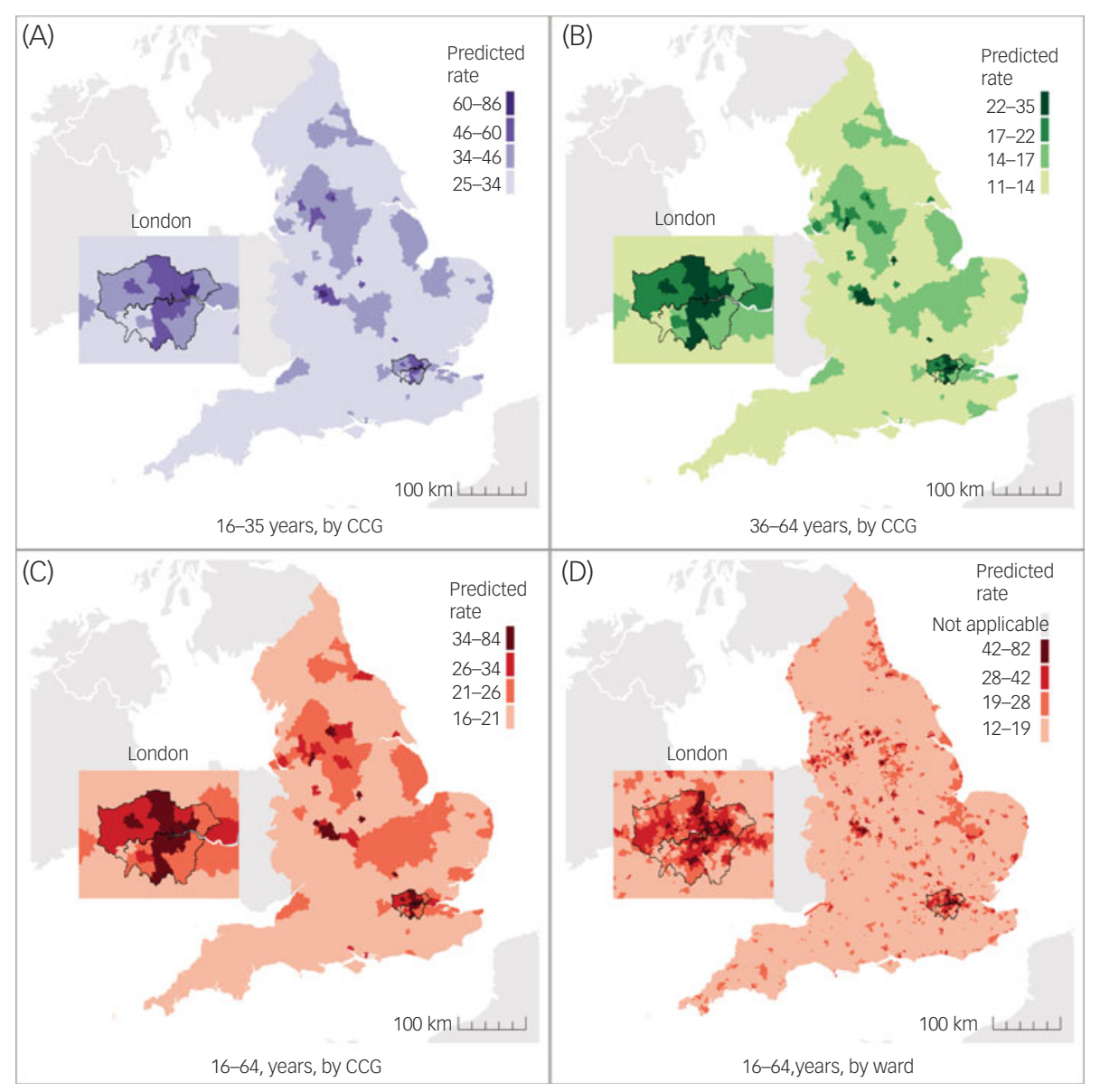

Fig. 1 Visualisation of predicted incidence rates of FEP per 100000 person-years by age and geographical level in England, 2020. Predicted incidence rate per 100000 person-years at the CCG level for people aged (A) 16-35 years, (B) 36-64 years, (C) 16-64 years and (D) at ward level for people aged 16-64 years. Predictions were not produced for five Census merged wards (Isles of Scilly [one ward] and all four wards within City of London) because of inaccurate population estimates, and values are not shown in (D). CCC, Clinical Commissioning Group; FEP, first-episode psychosis.

small-area variation in social and environmental factors, to validate an a priori set of candidate models against national routine data at the CCG level. Using Bayesian inference to model uncertainty around these predictions allowed us to forecast expected need for psychosis care in England up to 2025, within tolerable parameter estimates.

Prediction models are influenced by their underlying assumptions and limitations. Four issues are of particular note. First, our seed data included incident cases from approximately $10 \%$ of 2011 Census merged wards ( $n=751$ of 7678 ), covering $14.5 \%$ of CCGs in England. Predictions could be less accurate in areas that have very different sociodemographic or socioeconomic characteristics from those in our seed data-set regions. However, our best-fitting model displayed acceptable external validity to a national data-set at the CCG level, for total, gender- and ethnicity-specific case-loads in people aged 16-64 years. Second, our models under- and overestimated probable FEP case-loads in people aged 16-35 and 36-64 years, respectively, compared with observed data. This may have arisen from inclusion of epidemiological data in our seed data-set collected before the introduction of EIP services in England; $;^{30,33}$ there is some evidence that age at first contact with mental health services may have fallen since their introduction. ${ }^{31}$ Third, external validity of our models was reliant on the reliability and validity of observed FEP data from the MHSDS. Sensitivity analyses allowed us to validate our models in the presence of missing observed data on ethnicity.
Uncertainty in either our predictions or the observed data could explain deviance in our calibration plots at the CCG level. Since the MHSDS only provides information on who commenced EIP treatment, and not the subset of individuals who met diagnostic criteria for FEP, we revised observed treated case-loads downward by $14 \%$ to obtain a comparable FEP sample, in line with empirical evidence. ${ }^{31}$ This highlights the importance of recording reliable symptomatic and likely diagnostic outcomes in routine practice. Future models should include explicit predictions of people who meet CHR-P criteria for psychosis, implicitly included in our forecasts of new referred, assessed and treated case-loads per annum, but who could not be disaggregated because there is currently no provision to identify these groups separately in the MHSDS, upon which our forecasts were based. Fourth, our models did not account for predicted need in people aged $<16$ years (although absolute FEP incidence is $\operatorname{rare}^{50}$ ), or homeless or prison populations.

\section{Implications}

Our Bayesian population-level prediction model could be readily adapted and updated to forecast need beyond 2025, in other countries or for other disorders, where sufficiently reliable risk estimates and denominator data are available. Application to other countries, particularly the devolved nations in the UK, is both vital for public mental health and also offers the opportunity to establish the robustness of our models to populations with potentially different 
distributions of underlying risk factors for psychosis. ${ }^{16}$ Applied to FEP in England, our model provides healthcare commissioners with a decision-making tool to support the allocation of finite resources for EIP services, based on forecasts of need likely to arise in local populations, enhancing an earlier, more limited tool. ${ }^{18}$ Providing commissioners with access to evidence-based forecasts of such need should help optimise and fully implement NICEconcordant care for psychosis. ${ }^{20,22}$ This would provide the foundation for realising the demonstrable, evidence-based improvements in clinical and social outcomes for individuals experiencing FEP, as well as the cost-effectiveness benefits on which they were established. ${ }^{24,25,51,52}$ Moreover, optimal resource allocation in one mental health domain should propagate benefits to other areas of care for which mental health commissioners and planners are responsible. Our predictions also allow care providers to understand the likely sociodemographic and environmental characteristics of their case-loads, which may be useful for providing locally and regionally sensitive modes of care delivery across diverse communities.

Overall, we have developed and validated a generalisable, translational tool that used epidemiological data to forecast accurate estimates of future incidence of first-episode mental health disorders in different communities. The tool currently informs recently-updated NICE guidelines in England for EIP service provision. ${ }^{53}$ Our prediction methodology could be readily generalised to other settings or mental health problems underpinned by a precise, reliable epidemiology. Priorities here would include extension to predict people at clinical high risk of psychosis, ongoing recalibration in England, and extension and validation to other countries. Applied to psychosis care in England, our platform provides commissioners and providers with an open-access, evidence-based toolkit to optimise need for EIP care as and when it arises.

\section{Keltie McDonald (iD, Division of Psychiatry, University College London, UK; Tao Ding Department of Statistical Sciences, University College London, UK; Hannah Ker, Division of Psychiatry, University College London, UK; Thandiwe Rebecca Dliwayo, Division of Psychiatry, University College London, UK; David P.J. Osborn (D), Division of Psychiatry, University College London, UK; Pia Wohland, School of Earth and Environmental Sciences, University of Queensland, Australia; Hull-York Medical School, University of Hull, UK; Jeremy W. Coid (D), Mental Health Center and Psychiatric Laboratory, The State Key Laboratory of Biotherapy, West China Hospital of Sichuan University, China; \\ Paul French (D), Faculty of Health, Psychology and Social Care, Manchester \\ Metropolitan University, UK; Peter B. Jones, Department of Psychiatry, University of Cambridge, UK; Gianluca Baio, Department of Statistical Sciences, University College London, UK; James B. Kirkbride (D), Division of Psychiatry, University College London, UK}

Correspondence: James B. Kirkbride. Email: j.kirkbride@ucl.ac.uk

First received 14 Jul 2020, final revision 12 Oct 2020, accepted 28 Jan 2021

\section{Supplementary material}

To view supplementary material for this article, please visit https://doi.org/10.1192/bjp.2021.18.

\section{Data availability}

All PsyMaptic-A prediction data are freely available at www.psymaptic.org. We will share the online platform and the results from this study with NHS England, Clinical Commissioning Groups and national, regional and local EIP service leads for patient benefit. Because of the aggregated nature of the data included in this study, it is not possible to directly contact participants from the original studies included in our seed data-set.

\section{Acknowledgements}

We are very grateful to Jay Nairn, Amy Clark, Carl Money, Thomas Bardsley and Alison Brabban of NHS England, for their expertise and advice. We thank Carl Money and Thomas Bardsley for running our validation scripts on a non-supressed version of the MHSDS data at NHS England. We thank all EIP regional leads for their input into the initial results of the modelling process, which allowed us to further develop and refine our models. We are grateful to Gareth simons from Cityseer.io, for development of the 'PsyMaptic- $A$ ' web visualisation tool. We thank those who participated in the original AESOP, ELFEP and SEPEA studies, whose aggregated data has allowed us to develop a tool to inform future mental health service provision for psychosis in England. Written consent to cite personal communication was obtained from Carl Money, a copy of which is available on our preprint server (https://osf.io/pqrig/).

\section{Author contributions}

K.M. and T.D. contributed equally as co-first authors. T.D. and G.B. were responsible for development of the statistical prediction models. K.M. and J.B.K. were responsible for model validation. J.B.K. and P.B.J. conceived and designed the original inception of the work. T.R.D. assisted with data collection. H.K. assisted with data visualisation and preparation of figures. J.B.K., P.B.J. and J.W.C. provided access to empirical psychosis incidence data for the study. P.W. developed and provided the denominator forecasts. D.O., P.F. and P.B.J. provided clinical and service level expertise to inform model development. All authors contributed to the interpretation of results and critical review of the manuscript J.B.K. had full access to all the data in the study and had final responsibility for the decision to submit for publication.

\section{Funding}

This study was funded by an Enhancement Award from Wellcome Trust (101272/Z/13/A). This work was also supported by the National Institute for Health Research (NIHR), University College London Hospital, Biomedical Research Centre. D.O. is in part supported by the NIHR Applied Research Collaboration (ARC) North Thames. P.B.J. is supported by the Wellcome Trust (095844/Z/11/Z), the NIHR ARC East of England and the NIHR (RPPG-0616-20003). This report this publication reserch supported by the NIHR ARC North Thames. The views expressed in this publication are those of the author(s) and not necessarily those of the NIHR or the
Department of Health and Social Care.

\section{Declaration of interest}

P.B.J. has been a member of scientific advisory boards for Janssen and Ricordati. All other authors have no conflicts of interest to declare.

\section{References}

1 Henderson C, Robinson E, Evans-Lacko S, Corker E, Rebollo-Mesa I, Rose D, et al. Public knowledge, attitudes, social distance and reported contact regarding people with mental illness 2009-2015. Acta Psychiatr Scand 2016; 134: 23-33.

2 NHS England. The Five Year Forward View for Mental Health. The Mental Health Taskforce, 2016 (https://www.england.nhs.uk/wp-content/uploads/2016/02/ Mental-Health-Taskforce-FYFV-final.pdf).

3 Joint Commissioning Panel for Mental Health. Guidance for Commissioning Public Mental Health Services. Joint Commissioning Panel for Mental Health, 2012 (https://www.jcpmh.info/resource/guidance-for-commissioning-publicmental-health-services/).

4 Royal College of Psychiatrists. Whole-Person Care: from Rhetoric to Reality: Achieving Parity of Esteem between Mental and Physical Health, Vol. OP88 Royal College of Psychiatrists, 2013 (https://www.jcpmh.info/resource/wholeperson-care-from-rhetoric-to-reality/).

5 Dixon LB, Goldman H, Srihari VH, Kane JM. Transforming the treatment of schizophrenia in the United States: the RAISE initiative. Annu Rev Clin Psychol 2018; 14(1): 237-58.

6 Malla A, Shah J, Iyer S, Boksa P, Joober R, Andersson N, et al. Youth mental health should be a top priority for health care in Canada. Can J Psychiatry 2018; 63(4): 216-22.

7 McGorry P, Trethowan J, Rickwood D. Creating headspace for integrated youth mental health care. World Psychiatry 2019; 18(2): 140-1.

8 Ronis ST, Slaunwhite AK, Malcom KE. Comparing strategies for providing child and youth mental health care services in Canada, the United States, and The Netherlands. Adm Policy Ment Health 2017; 44(6): 955-66.

9 Csillag C, Nordentoft M, Mizuno M, McDaid D, Arango C, Smith J, et al. Early intervention in psychosis: from clinical intervention to health system implementation. Early Interv Psychiatry 2018; 12(4): 757-64.

10 Marshall M, Lewis S, Lockwood A, Drake R, Jones P, Croudace T. Association between duration of untreated psychosis and outcome in cohorts of first-episode patients: a systematic review. Arch Gen Psychiatry 2005; 62(9): 975-83

11 Correll CU, Galling B, Pawar A, Krivko A, Bonetto C, Ruggeri M, et al. Comparison of early intervention services vs treatment as usual for earlyphase psychosis. JAMA Psychiatry 2018; 75(6): 555.

12 Randall JR, Vokey S, Loewen H, Martens PJ, Brownell M, Katz A, et al. A systematic review of the effect of early interventions for psychosis on the usage of inpatient services. Schizophr Bull 2015; 41(6): 1379-86.

13 Aceituno D, Vera N, Prina AM, McCrone P. Cost-effectiveness of early intervention in psychosis: systematic review. Br J Psychiatry 2019; 215: 388-94.

14 Chan SKW, Chan HYV, Devlin J, Bastiampillai T, Mohan T, Hui CLM, et al. A systematic review of long-term outcomes of patients with psychosis who received early intervention services. Int Rev Psychiatry 2019; 31: 425-40.

15 McGrath JJ, Mortensen PB, Whiteford HA. Pragmatic psychiatric epidemiology -if you can't count it, it won't count. JAMA Psychiatry 2018; 75(2): 111-2. 
16 Oliver D, Reilly TJ, Baccaredda Boy O, Petros N, Davies C, Borgwardt S, et al What causes the onset of psychosis in individuals at clinical high risk? A metaanalysis of risk and protective factors. Schizophr Bull 2020; 46(1): 110-20.

17 Malla A, McGorry P. Early intervention in psychosis in young people: a population and public health perspective. Am J Public Health 2019; 109(S3): S181-4.

18 Kirkbride JB, Jackson D, Perez J, Fowler D, Winton F, Coid JW, et al. A population-level prediction tool for the incidence of first-episode psychosis: translational epidemiology based on cross-sectional data. BMJ Open 2013; 3(2): 1-14.

19 Kirkbride JB. Epidemiology on demand: population-based approaches to mental health service commissioning. BJPsych Bull 2015; 39(5): 242-7.

20 NHS England. Implementing the Early Intervention in Psychosis Access and Waiting Time Standard: Guidance. NHS England, 2016 (https://www.nice.org. uk/guidance/qs80/resources/implementing-the-early-intervention-in-psychosis-access-and-waiting-time-standard-guidance-2487749725).

21 Department of Health. Annual Report of the Chief Medical Officer 2013: Public Mental Health Priorities: Assessing the Evidence. Department of Health, 2014 (https://www.gov.uk/government/publications/chief-medical-officer-cmoannual-report-public-mental-health).

22 National Institute for Health and Care Excellence (NICE). Psychosis and Schizophrenia in Adults - Quality Standard [OS80]. NICE, 2015 (https://www. nice.org.uk/guidance/qs80).

23 National Institute for Health and Care Excellence (NICE). Psychosis and Schizophrenia in Adults: Prevention and Management - Clinical Guidance [CG178]. NICE, 2014 (https://www.nice.org.uk/guidance/cg178).

24 Bird V, Premkumar P, Kendall T, Whittington C, Mitchell J, Kuipers E. Early intervention services, cognitive-behavioural therapy and family intervention in early psychosis: systematic review. Br J Psychiatry 2010; 197(5): 350-6.

25 Stafford MR, Jackson H, Mayo-Wilson E, Morrison AP, Kendall T. Early interventions to prevent psychosis: systematic review and meta-analysis. $B M J$ 2013; 346(7892): f185.

26. Royal College of Psychiatrists. National Clinical Audit of Psychosis - National Report for the Early Intervention in Psychosis Spotlight Audit 2018/2019. Royal College of Psychiatrists, 2019 (https://www.hqip.org.uk/resource/nationalreport-for-the-early-intervention-in-psychosis-spotlight-audit-2018-2019/)

27 Office for National Statistics. Population Estimates for UK, England and Wales, Scotland and Northern Ireland: Mid-2018, using April 2019 Local Authority District Codes. Office for National Statistics, 2019 (https://www.ons.gov.uk/ peoplepopulationandcommunity/populationandmigration/ populationestimates)

28 NHS England. NHS Long-Term Plan. NHS England, 2019 (https://www.long termplan.nhs.uk/).

29 NHS England. NHS Mental Health Implementation Plan 2019/20-2023/24. NHS England 2019 (https://www.longtermplan.nhs.uk/wp-content/uploads/2019/ 07/nhs-mental-health-implementation-plan-2019-20-2023-24.pdf).

30 Kirkbride JB, Fearon P, Morgan C, Dazzan P, Morgan K, Tarrant J, et al. Heterogeneity in incidence rates of schizophrenia and other psychotic syndromes: findings from the 3-center AeSOP study. Arch Gen Psychiatry 2006; 63 (3): $250-8$.

31 Kirkbride JB, Hameed Y, Ankireddypalli G, Ioannidis K, Crane CM, Nasir M, et al The epidemiology of first-episode psychosis in early intervention in psychosis services: findings from the social epidemiology of psychoses in East Anglia [SEPEA] study. Am J Psychiatry 2017; 174(2): 143-53.

32 Kirkbride JB, Barker D, Cowden F, Stamps R, Yang M, Jones PB, et al. Psychoses, ethnicity and socio-economic status. Br J Psychiatry 2008; 193(1): 18-24.

33 Coid JW, Kirkbride JB, Barker D, Cowden F, Stamps R, Yang M, et al. Raised incidence rates of all psychoses among migrant groups: findings from the East London first episode psychosis study. Arch Gen Psychiatry 2008; 65(11): 1250-8.

34 Kirkbride JB, Errazuriz A, Croudace TJ, Morgan C, Jackson D, Boydell J, et al. Incidence of schizophrenia and other psychoses in England, 1950-2009: a systematic review and meta-analyses. PLOS One 2012; 7(3): e31660.

35 Moore THM, Zammit S, Lingford-Hughes A, Barnes TRE, Jones PB, Burke M et al. Cannabis use and risk of psychotic or affective mental health outcomes: a systematic review. Lancet 2007; 370(9584): 319-28.
36 Bourque F, Van Der Ven E, Malla A. A meta-analysis of the risk for psychotic disorders among first- and second-generation immigrants. Psychol Med 2011; 41(5): 897-910.

37 Hardoon S, Hayes JF, Blackburn R, Petersen I, Walters K, Nazareth I, et al. Recording of severe mental illness in United Kingdom Primary Care 2000-2010. PLOS One 2013; 8(12): e82365.

38 Rue H, Martino S, Chopin N. Approximate Bayesian inference for latent Gaussian models using integrated nested Laplace approximations (with discussion). J R Stat SOC B 2009; 71(2): 319-92.

39 Rees PH, Wohland P, Norman P, Lomax N, Clark SD. Population projections by ethnicity: challenges and solutions for the United Kingdom. In The Frontiers of Applied Demography Series 9 (ed. D Swanson): 383-408. Springer Publishing, 2017.

40 Lomax N, Wohland $\mathrm{P}$, Rees $\mathrm{P}$, Norman $\mathrm{P}$. The impacts of international migration on the UK's ethnic populations. J Ethn Migr Stud 2019; 46(1): 1-23.

41 Office for National Statistics. Mid-2001 to Mid-2017 Population Estimates for 2018 Wards in England and Wales by Single Year of Age and Sex. Office for lational Statistics, 2019 (https://www.ons gov. uk/peoplepopulationandcommunity/populationandmigration/populationestimates/adhocs/ 009583mid2001tomid2017populationestimatesfor2018wardsinenglandandwalesbysingleyearofageandsexexperimentalstatistics).

42 Smith T, Noble M, Noble S, Wright G, McLennan D, Plunkett E. The English Index of Multiple Deprivation (IMD) 2015 - Technical Report. UK Government, 2015 (https://www.gov.uk/government/publications/english-indices-of-deprivation-2015-technical-report).

43 Mcmanus S, Bebbington P, Jenkins R, Brugha T. Mental Health and Wellbeing in England: Adult Psychiatric Morbidity Survey 2014 Executive Summary. NHS Digital, 2016 (https://digital.nhs.uk/data-and-information/publications/statistical/adult-psychiatric-morbidity-survey/adult-psychiatric-morbidity-surveysurvey-of-mental-health-and-wellbeing-england-2014).

44 NHS Clinical Commissioners. About CCGs. NHS, 2021 (https://www.nhscc.org/ ccgs/).

45 Jongsma HE, Turner C, Kirkbride JB, Jones PB. International incidence of psychotic disorders, 2002-17: a systematic review and meta-analysis. Lancet Public Heal 2019; 4(5): e229-44.

46 Royal College of Psychiatrists, Early Intervention in Psychosis Network, College Centre for Quality Improvement. Self-Assessment for EIP Services. Royal College of Psychiatrists, 2021 (https://www.rcpsych.ac.uk/improving-care/ ccqi/quality-networks-accreditation/early-intervention-in-psychosis/selfassessment)

47 StataCorp. Stata Statistical Software: Release 15. StataCorp, 2017 (https:// www.stata.com/).

48 R Core Team. R: A Language and Environment for Statistical Computing. Version 1.9.1. R Foundation for Statistical Computing, 2013 (http://www.rproject.org/).

49 Kirkbride JB, Hameed Y, Ioannidis K, Ankireddypalli G, Crane CM, Nasir M, et al. Ethnic minority status, age-at-immigration and psychosis risk in rural environments: evidence from the SEPEA study. Schizophr Bull 2017; 43(6): 1251-61.

50 Okkels N, Vernal DL, Jensen SOW, McGrath JJ, Nielsen RE. Changes in the diagnosed incidence of early onset schizophrenia over four decades. Acta Psychiatr Scand 2012; 127(1): 62-8.

51 Birchwood M, Connor C, Lester H, Patterson P, Freemantle N, Marshall M, et al. Reducing duration of untreated psychosis: care pathways to early intervention in psychosis services. Br J Psychiatry 2013; 203(1): 58-64.

52 Csillag C, Nordentoft M, Mizuno M, Jones PB, Killackey E, Taylor M, et al. Early intervention services in psychosis: from evidence to wide implementation. Early Interv Psychiatry 2016; 10(6): 540-6.

$53 \mathrm{NHS}$. Implementing the Early Intervention in Psychosis Access and Waiting Time Standard: Guidance. NHS, 2020 (http://iris-initiative.org.uk/wordpress/ wp-content/uploads/2020/12/EIP-Guidance-2020_Final_2_KE.pdf).

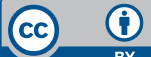

